\title{
Upendra Baxi in our times: law, life, liminality
}

\author{
Debolina Dutta $^{1} \cdot$ Adil Hasan Khan $^{2} \cdot$ Oishik Sircar $^{3}$
}

Published online: 5 December 2018

(C) O.P. Jindal Global University (JGU) 2018

This special issue of the Jindal Global Law Review (JGLR) is dedicated to Upendra Baxi. It brings together a diverse community of people whose lives, work and ways of thinking have been strongly influenced by Upen-as a teacher, mentor, comrade, colleague, parent.

As editors, the three of us have inherited Upen's work very differently. He has featured centrally in Debolina's and Adil's doctoral research; for Oishik, his presence looms large in his law teaching. In learning from each other about facets of Baxi that we had not attended to before, is where this project originated. We were supposed to organise a panel in honour of Upen at the 2018 Institute for Global Law and Policy Conference at Harvard Law School. The panel would have also featured Upen, and Shaun McVeigh as commentators. Unfortunately, the plan fell through. We realised that conversations around the influences and legacies of a scholar who has always been so attentive to enacting the task of creating broader scholarly communities in South Asia (and beyond) demanded that we broaden our engagement. It is then that we decided to put together this special issue and invite others to join in the conversation.

The pieces in this issue have been organized under three sections. The "symposium" section carries the full papers that were written for the panel (which didn't materialise!). It also features responses by Upen and Shaun. The "articles" section carries essays which are invited contributions. These speak in autobiographical, biographical and self-reflective voices about the experiences of being taught by

Debolina Dutta_PhD Scholar; Adil Hasan Khan-McKenzine Postdoctoral Fellow; Oishik SircarAssistant Professor.

Oishik Sircar

osircar@jgu.edu.in

Debolina Dutta

debolina26@gmail.com

Adil Hasan Khan

khan.a@unimelb.edu.au

1 Institute for International Law and the Humanities, Melbourne Law School, Carlton, Australia

2 McKenzie Postdoctoral Fellow, Melbourne Law School, Carlton, Australia

3 Jindal Global Law School, Sonipat, India 
Upen; teaching Upen's work in the classroom; teaching and resisting with Upen; philosophical, historical and activist learnings from Upen's writings; and vignettes about Upen's own formative years. The issue closes with the "interview" section that offers a dialogic engagement with Upen in the here and now with a focus on his life as a southern law teacher.

It has been an absolute pleasure curating this issue. It is a labour of love, friendship and solidarity. Working on it together has offered us a sense of calm in the midst of a range of personal travails. In the process of editing, we have learned immensely from reading the works of our contributors, and from Upen's generosity, care, wit and good humour. We thank Shaun McVeigh for agreeing to be a part of the symposium conversation. He has been a mentor to all three of us. We continue to learn from him about the responsibilities toward our jurisprudential inheritances and traditions.

We are very grateful to all our contributors, who so forthcomingly accepted our invitation and shared our enthusiasm about being a part of this issue celebrating Upendra Baxi's life, law and texts. This issue, we hope, offers a liminal insight into the richness and diversity of the inheritors of Upen's continuing legacy.

The student notes-editors at Jindal Global Law School-Aditya Vora, Apoorv Madan, Archana Yadav, Didon Misri, Gayatri Malhotra, Lakshya Gupta, Pranay Modi, Tanushri More, Varsha Banta, Vrinda Aggarwal-made the editing process much smoother than what we could have managed. We thank Vishwas H. Deviah, editor of $J G L R$, for giving us this opportunity to curate, what we think, is a very eclectic and exciting mix of writings. In many ways, the form and style of the writings are a tribute to Upen's own play with the conventions of legal scholarship. 